\title{
Signal peptide replacement resulted in recombinant homologous expression of laccase Lcc8 in Coprinopsis cinerea
}

\author{
Marcus Schulze ${ }^{1}$, Lukas Geisler ${ }^{1}$, Andrzej Majcherczyk ${ }^{2}$ and Martin Rühl ${ }^{* *}$
}

\begin{abstract}
Although the model agaricomycete Coprinopsis cinerea possess 17 different laccase genes, up to now only four $C$. cinerea laccases have been purified and characterized to some degree. By exchanging the nucleotide sequence of the deduced signal peptide of Lcc8 it was possible to homologously express Icc8 in C. cinerea under control of the Agaricus bisporus gdp/l promoter and the C. cinerea Iccl terminator. The purified Lcc8 showed two bands in the SDSPAGE with a molecular weight of $64 \mathrm{kDa}$ and $77 \mathrm{kDa}$, respectively. The IEF determined pl values of 3.3 and 3.4 for both bands. The optimal pH for oxidation of the substrates ABTS, 2,6-dimethoxyphenol, guaiacol and syringaldazine was $\mathrm{pH}$ 4.0, pH 5.0, pH 4.5 and pH 5.0, respectively. Best pH for enzyme storage was pH 8.0. The optimal temperature for oxidation of ABTS was $63^{\circ} \mathrm{C}$, while Lcc 8 showed activity of at least $50 \%$ over 300 min at $50^{\circ} \mathrm{C}$. The comparable high stability of Lcc8 at alkaline $\mathrm{pH}$ and higher temperatures can be of interest for biotechnical applications.
\end{abstract}

Keywords: Laccase, Coprinopsis cinerea, Signal peptide, Multi-copper oxidase, Purification, Biochemical characterization

\section{Introduction}

Laccases (EC 1.10.3.2, benzenediol: oxygen oxidoreductase) are phenoloxidases capable of oxidizing phenolic and aromatic compounds (Leonowicz et al. 2001). In nature, they are widespread in the fungal kingdom particularly in the phylum Basidiomycota, but they also occur in plants, insects and bacteria (Claus 2004). Since decades, fungal laccases are extensively studied and especially laccases of the fungal phylum Basidiomycota are in focus of research with respect to their production, biochemical characteristics and potential biotechnological use (Baldrian 2006; Giardina et al. 2010). However, up to now only a few applications are commercialized, amongst other reasons likely due to the generally low production yields of active enzymes. Supplementing fungal cultures with a wide range of aromatic alcohols and acids can led to elevated laccase yields (Leonowicz et al. 2001; de

\footnotetext{
*Correspondence: martin.ruehl@uni-giessen.de

${ }^{1}$ Institute of Food Chemistry and Food Biotechnology, Justus Liebig University Giessen, Heinrich-Buff-Ring 17, 35392 Giessen, Germany Full list of author information is available at the end of the article
}

Souza et al. 2004). Even a fungus/fungus co-culture was able to increase the native laccase activity in the culture supernatant ( $\mathrm{Hu}$ et al. 2018). Recombinant expression of laccases for the purpose of high enzyme titers is normally attempted in heterologous ascomycetous hosts, such as yeasts, Aspergillus species or other filamentous ascomycetes (Mate and Alcalde 2015; Hong et al. 2002; Larrondo et al. 2003; Kiiskinen et al. 2004; Hong et al. 2007). However, a very high titer of recombinant enzyme has been achieved with the homologous expression of the lac1 gene in the basidiomycete Pycnoporus cinnabarinus (Alves et al. 2004) with a laccase yield of $1.2 \mathrm{~g} \mathrm{~L}^{-1}$. Unfortunately, research on basidiomycetous expression systems for industrial relevant enzymes is spare and might be underestimated, resulting in limited studies on recombinant laccase production in fungi of the phylum Basidiomycota.

In higher fungi, laccase genes often occur in larger families (Hoegger et al. 2006; Kües and Rühl 2011) resulting in different isoenzymes (Bollag and Leonowicz 1984; Rühl et al. 2013). The genome of the model 
organism C. cinerea contains 17 laccase genes (Hoegger et al. 2004), but only a handful of derived isoenzymes have been detected in cultures of various $C$. cinerea strains. In submerged cultures of $C$. cinerea monokaryons, amongst them FA2222, laccases Lcc1 and Lcc5 are the main isoenzymes, whereas Lcc2, Lcc9 and Lcc10 were only present sporadically (Rühl et al. 2013). In the C. cinerea monokaryon Okayama 7, co-culture with the Mucoromycete Gongronella sp. w5 was able to induce Lcc9 as major enzyme (Pan et al. 2014; Hu et al. 2018), leading to the assumption that Lcc9 possibly takes part in the defense response of $C$. cinerea. Beside these native C. cinerea laccases, several studies focused on their recombinant production for functional studies (Schneider et al. 1999). Nevertheless, characteristics of only four laccases (Lcc1, Lcc2, Lcc6 and Lcc9) have been published (Schneider et al. 1999; Pan et al. 2014; Tian et al. 2014; Wang et al. 2014). In this study, we were able to express the yet uncharacterized Lcc8 of C. cinerea homologously by exchanging the native signal peptide of Lcc8.

\section{Materials and methods}

Chemicals were purchased from Sigma-Aldrich (Steinheim, Germany), Amresco (VWR, Germany), Biozyme (Oldendorf, Germany), AppliChem (Darmstadt, Germany), Merck (Darmstadt, Germany). PCR primers were ordered from Eurofins MWG Operon (Ebersberg, Germany) or Biomers (Ulm/Donau, Germany).

\section{Strains, culture media and culture conditions}

Escherichia coli strain JM109 was used for propagation of plasmid DNA. It was cultivated in Lennox-LB media (Carl Roth, Karlsruhe, Germany) supplemented with $50 \mu \mathrm{g} \mathrm{L}^{-1}$ ampicillin (Carl Roth) at $37^{\circ} \mathrm{C}$ and $180 \mathrm{rpm}$. Saccharomyces cerevisiae strain RH1385 (MATaAura3, Mösch et al. 1990) was used for homologous recombination of expression plasmids (Gietz and Schiestl 2007) as described previously (Galperin et al. 2016). Coprinopsis cinerea strain FA2222 (DSM 28333) was used as the expression host. Cultivation on agar plates and transformation was carried out according to Dörnte and Kües (2012). Submerged cultivation of positive transformants was conducted in modified Kjalke (mKjalke) medium (Rühl et al. 2013) supplemented with $0.1 \mathrm{mM} \mathrm{CuSO}_{4}$.

\section{Gene amplification}

Total gDNA of C. cinerea strain FA2222 was isolated from fungal mycelia according to Liu et al. (2000). For amplification of the $l c c 8$ gene (Hoegger et al. 2004; gene accession number AY338764) via PCR from gDNA, a primer pair was used with homologous overlaps to the DNA regions of the gpdII-promotor and lcc1-terminator present in the pYSK7 plasmid (Kilaru et al. 2006a, b): pYMS33_for (5'-TTCTGTCGATACCATGACCCT CACCAACGCAAACTTGTCGCCGGATGGCT-3') and pYMS33_rev (5'-GCCCTCTGGTCAACTATAATATTA TTCACGACGAATCAGTAGCCGCAGCA-3'). PCR was performed using the Phusion ${ }^{\circledR}$ High-Fidelity DNA Polymerase Kit (New England Biolabs, Frankfurt, Germany) according to the instruction manual. pYSK7 was linearized by restriction digestion using the enzymes FD-HpaI and FD-BamHI (ThermoScientific, Schwerte, Germany) according to manufacturer's instructions. The PCR products and the linear fragments derived from pYSK7 were detected via agarose gel electrophoresis and purified from gel pieces using the NucleoSpin PCR cleanup Kit (Macherey-Nagel, Düren, Germany). Yeast strain RH1385 was transformed with the PCR product of pYMS33_for/rev and the linearized pYSK7 for homologous recombination as described elsewhere (Galperin et al. 2016) to generate the final plasmid pYMS33. Clones were analyzed by colony PCR using pYSK7 expression cassette specific primers (gpdII_for 5'-CCATCTCCG TTTTCTCCCATC-3'; lcc1-term_rev 5'-CTGGCCCTC TGGTCAACTATAAT-3').

\section{Plasmid DNA isolation from S. cerevisiae RH1385}

Positive yeast clones, proofed by colony PCR, were used for plasmid DNA isolation. A $10 \mathrm{~mL}$ YSDO overnight culture of positive clones was spun down for $5 \mathrm{~min}$ at $500 \mathrm{~g}$ to sediment cells. Supernatant was discarded and

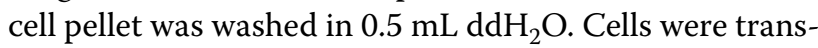
ferred to $1.5 \mathrm{~mL}$ Eppendorf tube and spun down again for $5 \mathrm{~s}$ at $18,000 \mathrm{~g}$. Supernatant was discarded and the cell pellet was dissolved in residual liquid. $200 \mu \mathrm{L}$ yeast lysis buffer (4 mL Trition $\mathrm{x}-100,20 \mathrm{~mL} 10 \%$ SDS, $4 \mathrm{~mL}$ $5 \mathrm{M} \mathrm{NaCl}, 400 \mu \mathrm{L} 0.5 \mathrm{M}$ EDTA, $2 \mathrm{~mL} 1 \mathrm{M}$ Tris pH 8.0, filled up to $200 \mathrm{~mL}$ with $\mathrm{ddH}_{2} \mathrm{O}$ ), $200 \mu \mathrm{L}$ phenol:chlorof orm:isoamylalcohol (25:24:1) and $0.3 \mathrm{~g}$ acid washed glass beads $(425-600 \mu \mathrm{m})$ were added to the yeast cells in this sequence. The cells were vortexed for $10 \mathrm{~min}$ and $200 \mu \mathrm{L}$ TE-buffer ( $\mathrm{pH}$ 8.0) was added. After 5 min centrifugation, $400 \mu \mathrm{L}$ of the aqueous phase was transferred to a new tube. $40 \mu \mathrm{L} 3 \mathrm{M}$ sodium acetate ( $\mathrm{pH} 5.5)$ and $1 \mathrm{~mL}$ of $96 \%$ ethanol were added and mixed. The preparation was placed for $15 \mathrm{~min}$ in $-20^{\circ} \mathrm{C}$ and afterwards spun down for $20 \mathrm{~min}$. Supernatant was discarded and $400 \mu \mathrm{L}$ TE buffer and $4 \mu \mathrm{L}$ RNase A $\left(10 \mathrm{mg} \mathrm{mL}^{-1}\right)$ were added to the nucleic acid pellet. RNA was digested for $15 \mathrm{~min}$ at $37^{\circ} \mathrm{C}$. $10 \mu \mathrm{L}$ of $4 \mathrm{M}$ ammonium acetate and $1 \mathrm{~mL}$ of $96 \%$ ethanol were added and mixed again. The nucleic acids were spun down again for $2 \mathrm{~min}$ and supernatant was discarded. The DNA-pellet was washed with $500 \mu \mathrm{L} 70 \%$ ethanol for $5 \mathrm{~min}$. After removing ethanol and drying the pellet,

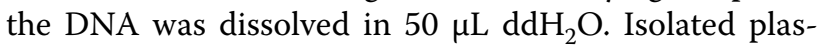
mid DNA was used for electro-transformation of $E$. coli 
JM109 with the Eppendorf Eporator ${ }^{\circledR}$ (Eppendorf, Hamburg, Germany). Plasmid pYMS33 was extracted from E. coli and sequenced by SeqLab (Göttingen, Germany). C. cinerea strain FA2222 was co-transformed according to the transformation protocol of Dörnte and Kües (2012) with 1-2 $\mu \mathrm{g}$ of the marker plasmid pCc1001 complementing the tryptophan auxotrophy of FA2222 and with the same amount of pYMS33. Additionally, pCc1001 was transformed solely into FA2222 to obtain a control transformant. Picked clones were grown on minimal

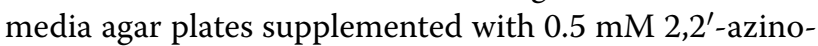
bis-(3-ethylbenzthiazoline-6-sulfonate) diammonium salt (ABTS; AppliChem GmbH, Darmstadt, Germany) until a faint coloring appeared. Transformants which were positive in the ABTS plate assay were set on minimal media plates and cultured for 3-4 days. When there was enough mycelia a fast microwave based DNA extraction was performed according to the method of Dörnte and Kües (2013) to verify successful integration of the recombinant $l c c 8$ expression cassette into the $C$. cinerea genome by means of colony PCR using the pYSK7 expression cassette specific primers (gpdII_for 5'-CCATCTCCGTTT TCTCCCATC-3'; lcc1-term_rev 5'-CTGGCCCTCTGG TCAACTATAAT-3').

\section{Laccase purification}

At the day of highest laccase activity, the supernatant of pYMS33 clone 12 culture was harvested and filtered by folded filter MN616 ${ }^{1 / 4}$ Ø270 mm (Macherey-Nagel, Düren, Germany). The $\mathrm{pH}$ of supernatant was adjusted to $\mathrm{pH} 6.4$ followed by centrifugation at $4700 \mathrm{~g}$ at $4{ }^{\circ} \mathrm{C}$ for $30 \mathrm{~min}$ and filtered again. Before using a FPLC-column the supernatant was filtered with an Ultrasette ${ }^{\mathrm{TM}}$ Screen Channel TFF Device (Pall, Dreieich, Germany) to exclude all particles bigger than $300 \mathrm{kDa}$. All FPLC purification steps were performed with columns of GE Healthcare (Freiburg, Germany) and using the BioLogic DuoFlow system of Bio-Rad (Düsseldorf, Germany). The ultrafiltrated supernatant was applied to DEAE-FF anion

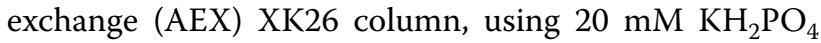
(pH 6.4) as loading buffer and $20 \mathrm{mM} \mathrm{KH}_{2} \mathrm{PO}_{4}+1 \mathrm{M}$ $\mathrm{NaCl}$ as elution buffer. Collected fractions were screened for laccase activity by ABTS assay and active fractions were pooled. Pooled fractions were filtered using the VivaFlow 200 with a $10 \mathrm{kDa}$ membrane (Sartorius, Göttingen, Germany) and thereby were resalted with loading buffer $20 \mathrm{mM} \mathrm{KH}_{2} \mathrm{PO}_{4}+1 \mathrm{M}\left(\mathrm{NH}_{4}\right)_{2} \mathrm{SO}_{4}$ for hydrophobic interaction chromatography (HIC). A HiPrep16/10 highsub column with Phenyl FF as solid phase was used for the HIC. HIC fractions were eluted with $20 \mathrm{mM} \mathrm{KH}_{2} \mathrm{PO}_{4}$. Collected fractions were screened again for laccase activity, pooled and desalted.

\section{Laccase activity assay}

Laccase activity was determined in 96-well plates at room temperature with $10 \mathrm{mM}$ ABTS in $150 \mathrm{mM}$ sodium acetate buffer at $\mathrm{pH} 5.0$ as described earlier by Rühl et al. (2013). Oxidation of ABTS into its cation radical (ABTS ${ }^{+}$) was measured by an increase of absorbance at $420 \mathrm{~nm}\left(\varepsilon=36.000 \mathrm{M}^{-1} \mathrm{~cm}^{-1}\right)$ for $10 \mathrm{~min}$ (Johannes and Majcherczyk 2000). One unit of activity was defined as the amount of enzyme needed to oxidize $1 \mu \mathrm{mol}$ ABTS per min and activities are given in $U$ per volume.

\section{Enzyme analysis \\ Electrophoresis and staining}

For separation of proteins and detection of laccases, samples were applied to SDS-PAGE according to Laemmli (1970) with $4 \%$ stacking and $12 \%$ resolving polyacrylamide gels. Laccase zymogram was performed according to Rühl et al. (2013). Silver staining of an SDS gel was performed according to Blum et al. (1987), (Table 1). Colloidal Coomassie staining was performed according to Dyballa und Metzger (2009).

\section{Isoelectric focusing}

For determination of the pI values the SERVAGel ${ }^{\mathrm{TM}}$ IEF 3-10 system was used according to manufacturer's manual. $20 \mathrm{mU}$ of purified laccase for native staining were used. The SERVA IEF Marker 3-10 liquid mix was used for determination of the $\mathrm{pI}$ values. Native staining was performed according to Rühl et al. (2013).

Table 1 Purification of Lcc8 from culture supernatant

\begin{tabular}{lllccc}
\hline Purification step & $\begin{array}{l}\text { Total laccase activity } \\
{[\mathbf{U}]}\end{array}$ & $\begin{array}{l}\text { Total protein amount } \\
{[\mathbf{m g}]}\end{array}$ & $\begin{array}{l}\text { Specific activity [U/ } \\
\mathbf{m g}]\end{array}$ & $\begin{array}{l}\text { Yield [\%] } \\
\text { factor }\end{array}$ & $\begin{array}{l}\text { Purification } \\
\text { Supernatant }\end{array}$ \\
Ultrafiltration & 133 & 28.6 & 4.7 & 90 & 1.0 \\
AEX & 127 & 22.7 & 5.6 & 65 & 1.2 \\
HIC & 85 & 5.4 & 15.7 & 19 & 3.3 \\
\hline
\end{tabular}




\section{Protein identification}

Protein bands of the Coomassie- or native stained gels corresponding to laccase activity were cut with a razor blade and transferred to $1.5 \mathrm{~mL}$ LoBind tubes (Eppendorf, Hamburg, Germany). Gel pieces were washed and proteins digested as previously described (Gundry et al. 2009). Briefly, gels were washed with $50 \%$ methanol (0.1\% formic acid), destained with $50 \mathrm{mM}$ ammonium bicarbonate in $50 \%$ acetonitrile, washed with water and dehydrated with acetonitrile. Proteins were reduced with 1,4-dithiothreitol and alkylated with iodoacetamide. Finally, proteins were digested in-gel by trypsin at $37{ }^{\circ} \mathrm{C}$ overnight. Extracted peptides were further purified on self-made C18-STAGE tips (Rappsilber et al. 2007). Peptides were analyzed by nanoLC (Eksigent 425, Sciex) coupled to TripleTOF 5600+ mass spectrometer (Sciex, Darmstadt, Germany) and raw MS-data were processed using ProteinPilot (Sciex). The protein fasta-file of $C$. cinerea AmutBmut pab1-1 (v1.0) used for data searches was downloaded (https://genome.jgi.doe.gov/Copci _AmutBmut1/Copci_AmutBmut1.home.html) from JGI (DOE, Walnut Creek, CA, USA).

\section{Biochemical characterization}

Besides ABTS some other substrates were used for determination of laccase activity, which were 2,6-dimethoxyphenol (DMP), 2-methoxyphenol (guaiacol) and syringaldazine (SGZ, 4-hydroxy-3,5-dimethoxybenzaldehyde azine). The increase of extinction was observed spectroscopically at $420 \mathrm{~nm}\left(\varepsilon=36.000 \mathrm{M}^{-1} \mathrm{~cm}^{-1}\right)$, $468 \quad \mathrm{~nm} \quad\left(\varepsilon=49.600 \quad \mathrm{M}^{-1} \quad \mathrm{~cm}^{-1}\right), \quad 436 \quad \mathrm{~nm}$ $\left(\varepsilon=6.400 \mathrm{M}^{-1} \mathrm{~cm}^{-1}\right)$ and $526 \mathrm{~nm}\left(\varepsilon=65.000 \mathrm{M}^{-1} \mathrm{~cm}^{-1}\right)$ for ABTS, DMP, guaiacol and syringaldazine, respectively (Matsumura et al. 1986; Wariishi et al. 1992; Slomczynski et al. 1995; Eggert et al. 1996). One unit of enzyme activity was defined as the amount of enzyme oxidizing $1 \mu \mathrm{mol}$ substrate per min. For determination of the optimal $\mathrm{pH}$-value Britton-Robinson universal buffer $\mathrm{pH} 2-12$ was used. The $\mathrm{pH}$ stability was determined by incubating $150 \mathrm{mU}$ laccase in $1 \mathrm{~mL}$ universal buffer ( $\mathrm{pH} 2-12$ ) for up to $24 \mathrm{~h}$. At defined intervals, samples were collected and laccase activity was measured with ABTS in $150 \mathrm{mM}$ sodium acetate buffer (pH 5.0). For the determination of the optimal temperature, the laccase activity was measured at the temperatures ranging from 11 to $71^{\circ} \mathrm{C}$ with ABTS in $150 \mathrm{mM}$ sodium acetate buffer (pH 5.0) using cuvettes. The reaction temperature has been measured directly in the cuvettes resulting in the distinct values of $11{ }^{\circ} \mathrm{C}, 20^{\circ} \mathrm{C}, 28{ }^{\circ} \mathrm{C}, 36^{\circ} \mathrm{C}, 45^{\circ} \mathrm{C}, 54{ }^{\circ} \mathrm{C}$, $63{ }^{\circ} \mathrm{C}$ and $71^{\circ} \mathrm{C}$. The thermal stability was determined by incubation of the laccase in universal buffer $\mathrm{pH} 8$ for at least $5 \mathrm{~h}$ at $10{ }^{\circ} \mathrm{C}, 30{ }^{\circ} \mathrm{C}, 50{ }^{\circ} \mathrm{C}$ and $70{ }^{\circ} \mathrm{C}$. The activity was measured with ABTS in $150 \mathrm{mM}$ sodium acetate buffer (pH 5.0).

Deglycosylation of Lcc8 was performed with PNGase $F$ according to the manufacturer protocol (New England Biolabs, Frankfurt, Germany) and monitored by SDSPAGE (see above).

\section{Results}

To express laccase Lcc8 homologously in C. cinerea, the most suitable plasmid pYSK7 constructed by Kilaru et al. (2006b) for the expression of Lcc1 was modified in this study. The $l c c 8$ construct was introduced into the linearized pYSK7 plasmid via homologus recombination in the yeast Saccharomyces cerevisiae RH1385. The resulting plasmid pYMS33 comprised of the $l c c 8$ gene under control of the glyceraldehyde 3-phosphate dehydrogenase II (gpdII) promotor from Agaricus bisporus and the lcc1-terminator of $C$. cinerea laccase lcc1 both revealed to be functional in $C$. cinerea laccase expression (Kilaru et al. 2006b). Two transformations of $C$. cinerea strain FA2222 with pYMS33 (Additional file 1: Figure S1) resulted in a total number of 80 transformants. All pYMS33 transformants as well as four pCc1001 control transformants were cultivated on ABTS supplemented agar plates for up to 3 days at $37{ }^{\circ} \mathrm{C}$. For almost all transformants a very faint coloration was observed, whereas one pYMS33 transformant (pYMS33-12) showed a distinct green halo. PCR of pYMS33-12 genomic DNA using primers gpdII_for and $l c c 1$-term_rev confirmed the presence of the $l c c 8$ expression cassette in pYMS33-12. Submerged cultivation of pYMS33-12 in mKjalke medium supplemented with $0.1 \mathrm{mM} \mathrm{CuSO}_{4}$ resulted in increasing laccase production in the supernatant with a maximum activity of $250 \mathrm{U} \mathrm{L}^{-1}$ at day 5 of cultivation (Fig. 1). With ongoing cultivation, pYMS33-12 showed a rapid decrease in

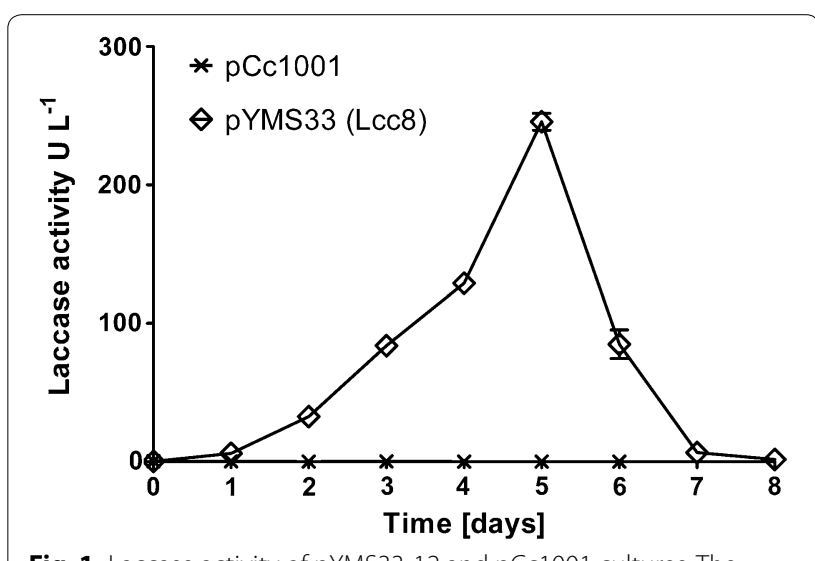

Fig. 1 Laccase activity of pYMS33-12 and pCc1001 cultures. The laccase activity was monitored by ABTS assay 
laccase activity until the end of cultivation. In parallel cultures of the control transformant pCc1001, no laccase activity was observed during the whole cultivation.

The supernatant of a subsequent cultivation of pYMS33-12 in the same medium was used to purify Lcc8. Consecutive purification steps (ultrafiltration, anion exchange chromatography-AEX, and hydrophobic interaction chromatography-HIC) resulted in a final purification factor of 10 , which accounts for a specific laccase activity of $46.3 \mathrm{U} \mathrm{mg}^{-1}$ (Table 1 ). Thus, around one-fifth (19\%) of the laccase activity from the supernatant remained in the purified sample.

SDS-PAGE reveals increasing band intensity for two bands with the sizes $64 \mathrm{kDa}$ and $77 \mathrm{kDa}$ correlating with the grade of purification (Fig. 2). In addition, a smaller band of around $50 \mathrm{kDa}$ is present in the HIC fraction. A laccase zymogram of the HIC fraction stained with the substrate mixture 3-methyl-2-benzothiazolinone-hydrazone hydrochloride $(\mathrm{MBTH})$ and 3,4-dihydroxyhydrocinnamic acid (DHPPA), which is known to be highly efficient for laccase activity staining (Rühl et al. 2013), shows two main laccase bands for the purified pYMS33-12 fraction (Fig. 3a). Furthermore, the laccase activity bands for Lcc8 showed a different running pattern in the SDS-PAGE in correlation to the control laccases Lcc1 and Lcc5 both showing only one main laccase band.

The two putative Lcc8 laccase bands (Fig. 3a) of a zymogram were cut and analyzed by nano-LC-MS/MS. The proteomic analysis revealed that both analyzed bands belong to the $C$. cinerea laccase Lcc8 (Additional file 1: Table S1).

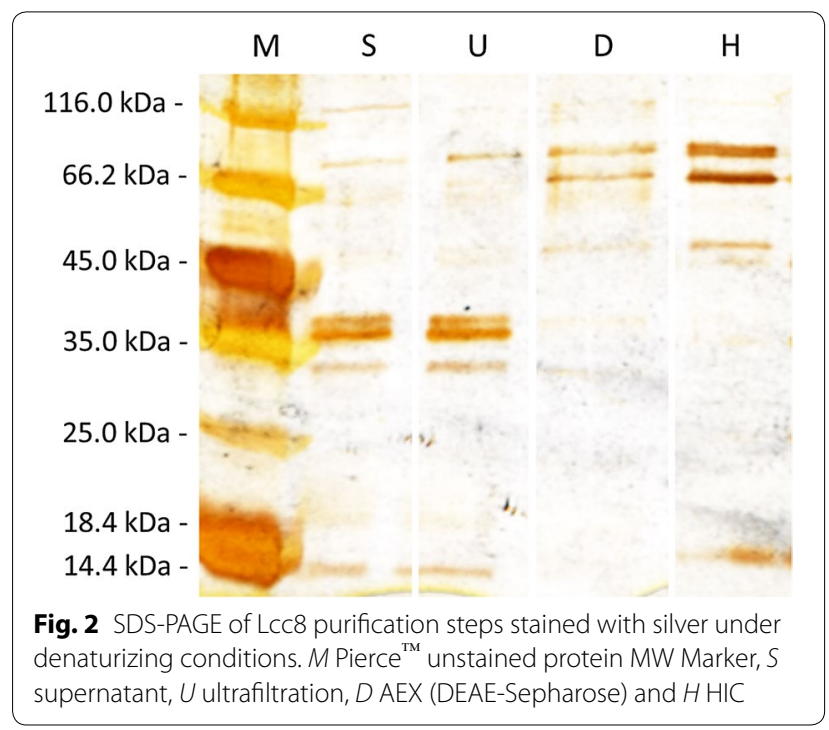

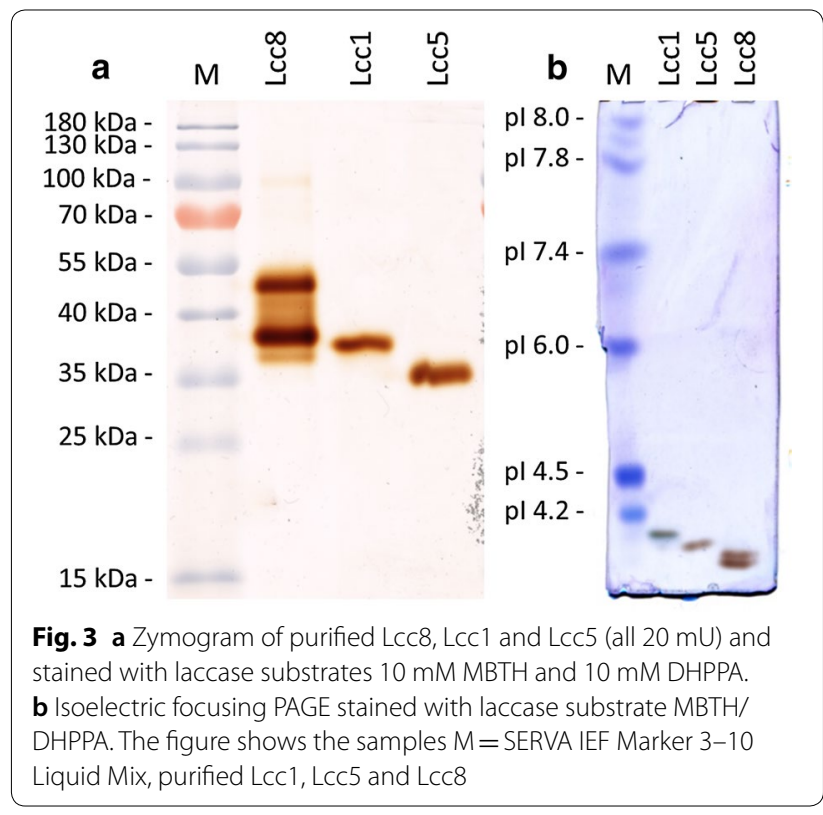

\section{Laccase characterization}

For determination of pI-values an isoelectric focusing (IEF) was performed and proteins were stained with the laccase specific substrate mixture MBTH and DHPPA. The IEF (Fig. 3b) shows two active laccase bands in the Lcc8 fraction with a lower $\mathrm{pI}$ than the control laccases Lcc1 and Lcc5. Extrapolation of marker pIs led to pI-values of about 3.3 and 3.4, respectively. Activity assays with four different substrates in the $\mathrm{pH}$ range from $\mathrm{pH} 2$ to $\mathrm{pH}$ 12 showed highest enzyme activities between $\mathrm{pH} 3.5$ and $\mathrm{pH} 5.0$ and no laccase activity could be detected below a $\mathrm{pH}$ of 2.5 or above 6.0. Lcc8 showed optimal conditions for the oxidation of ABTS at a pH of 3.5-4.0, DMP at a $\mathrm{pH}$ 5.0, guaiacol at a $\mathrm{pH}$ of 4.5 and SGZ at a pH of 5.0 (Fig. 4a). The optimal temperature for Lcc8 using ABTS as a substrate was $63{ }^{\circ} \mathrm{C}$, although at this temperature the activity was stable only for $5 \mathrm{~min}$ and then decreased slowly. At temperatures of $54{ }^{\circ} \mathrm{C}$ and below, no decrease in activity was observed during measurement. Higher temperatures than $63{ }^{\circ} \mathrm{C}$ led to a quick deactivation of Lcc8 and resulted in decreased laccase activity (Fig. 4b).

Testing of storage stability of Lcc8 in universal buffer at different $\mathrm{pH}$ values showed that Lcc8 is stable in an alkaline $\mathrm{pH}$-range. Surprisingly, at least $50 \%$ of the enzyme activity remained after $48 \mathrm{~h}$ in buffers from $\mathrm{pH}$ 6 to $\mathrm{pH} 11$, with highest stability at around $\mathrm{pH} 8$ (Fig. 4c). Accordingly, Lcc8 was mixed with universal buffer $\mathrm{pH} 8$ to reveal the temperature stability (Fig. 4d). After $30 \mathrm{~min}$ at a temperature of $70{ }^{\circ} \mathrm{C}, \mathrm{Lcc} 8$ showed no activity. This correlates with the results of the determination of the optimal reaction temperature, where already after $3 \mathrm{~min}$ at $71{ }^{\circ} \mathrm{C}$ the activity decreased rapidly. At a temperature 

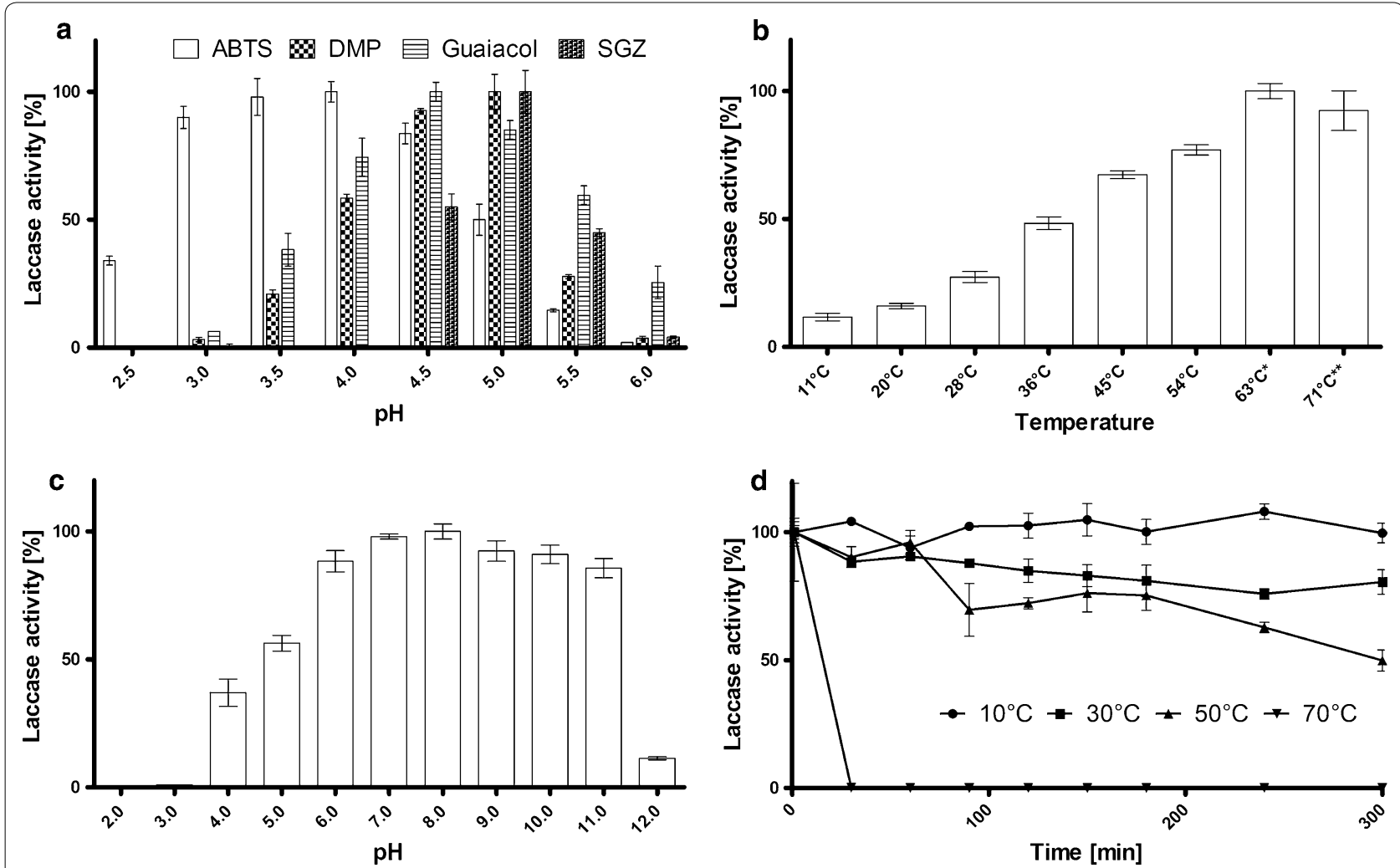

Fig. 4 Characterization of Lcc8. a Detection of substrate specificity and pH optimum. $\mathbf{b}$ Detection of optimal reaction temperature with ABTS. ${ }^{*}$ The activity was stable for $5 \mathrm{~min}$ and then began to decrease slowly. ${ }^{*}$ The activity was stable for $3 \mathrm{~min}$ and then began to decrease rapidly. $\mathbf{c}$ Analysis of optimal storage $\mathrm{pH}$. d Enzyme stability at different temperatures

of $50{ }^{\circ} \mathrm{C}$, Lcc 8 was more stable, remaining $50 \%$ of its activity after $300 \mathrm{~min}$. Lower temperatures showed minimal $\left(30^{\circ} \mathrm{C}\right)$ or no $\left(10^{\circ} \mathrm{C}\right)$ activity loss over a tested period of $300 \mathrm{~min}$ at $\mathrm{pH} 8$.

\section{Discussion}

Laccases of C. cinerea cluster into two distinct groups, the larger laccase sensu stricto subfamily 1 and the smaller subfamily 2 (Kües and Rühl 2011). Within subfamiliy 1 , Lcc8 is outlined from the other $C$. cinerea laccases (Kilaru et al. 2006a) assuming a special role in $C$. cinerea. In a previous work, Kilaru et al. (2006a) was not successful in homologous expression of Lcc8. Neither the native $l c c 8$ sequence nor the "long $l c c 8$ " sequence, which started 412 bp upstream of the predicted start codon, resulted in an active laccase. The SignalP 4.1 algorithm (Petersen et al. 2011) predicted no signal sequence for the Lcc8 amino acid sequence (accession number: BK004118), but one signal sequence of 23 amino acid length for the long Lcc8 (accession number: A8N4I7). The missing signal peptide in Lcc8 and the yet not detected Lcc8 peptides in analyzed C. cinerea wild type cultures (Rühl et al. 2013; Hu et al. 2018) led to the assumption that Lcc8 might not be transported outside of the fungal cell and, thus, acting intracellularly. By exchanging the $\mathrm{N}$-terminal sequence of the Lcc8 with the signal peptide of Lcc1 (Additional file 1: Figures S1 and S2), known to be constantly expressed, a successful expression of Lcc8 was possible. Although in contrast to previous studies on recombinant enzyme production in C. cinerea (Kilaru et al. 2006b; Galperin et al. 2016), co-transformation experiments in this work resulted only in one distinct positive clone out of 80 tested clones accounting for a poor co-transformation efficiency of only $1.25 \%$. Generally, efficiencies of more than $40 \%$ and $50 \%$ are possible as we could show in earlier co-transformations with $C$. cinerea using pCc1001 as marker plasmid (Kilaru et al. 2006a, b; Galperin et al. 2016). The poor transformation efficiency for Lcc8 expression can be due to an insufficient plasmid DNA concentration, which is very important for high transformation efficiencies. For a co-transformation of C. cinerea, Dörnte and Kües (2016) showed that lowering the amount of expression plasmid, while applying a constant concentration of marker plasmid pCc1001, lead to a reduced number of clones and to a low co-transformation efficiency of only $5-10 \%$. 
Another explanation might be that positive clones have been overlooked due to their low laccase activity resulting in no observable oxidation of ABTS during cultivation on agar plates for up to 3 days. Nevertheless, PCR and peptide analysis confirmed the integration of the expression cassette and the expressed laccase to be Lcc8.

The positive transformant pYMS33-12 was cultured in liquid medium under conditions where native laccases are not produced (Kilaru et al. 2006a, b; Rühl et al. 2013). This was confirmed by the cultivation of the control transformant pCc1001 under the same conditions showing any laccase activity during submerged fermentation over a period of 8 days (Fig. 1). The obtained maximal laccase activity of around $0.25 \mathrm{U} \mathrm{mL}^{-1}$ in pYMS33-12 cultures is ten times lower than in comparable cultures of the C. cinerea transformant pYSK7 producing the $C$. cinerea laccase Lcc1. Kilaru et al. (2006b) demonstrated that the pYSK7 transformant cultivated in YMG (yeast, malt extract, glucose) medium supplemented with $0.1 \mathrm{mM}$ $\mathrm{CuSO}_{4}$ showed a maximal activity of $3 \mathrm{U} \mathrm{mL}^{-1}$. This activity was dramatically higher than in cultures without the addition of $0.1 \mathrm{mM} \mathrm{CuSO}_{4}$ (Kilaru et al. 2006b). A similar activity of $2.9 \mathrm{U} \mathrm{mL}^{-1}$ was achieved when pYSK7 was cultivated in mKjalke medium supplemented with $0.1 \mathrm{mM} \mathrm{CuSO}_{4}$ at $37^{\circ} \mathrm{C}$ (Rühl et al. 2018). Laccases are multi-copper oxidases, which require four copper atoms per active laccase molecule (Messerschmidt 1997). Thus, addition of $\mathrm{CuSO}_{4}$ is generally applied to yield high amounts of active enzymes (Larrondo et al. 2003; Kilaru et al. 2006b). The protein yield of Lcc8 calculated on basis of its specific activity $\left(46.3 \mathrm{U} \mathrm{mg}^{-1}\right)$ and volumetric activity $\left(250 \mathrm{U} \mathrm{L}^{-1}\right)$ was around $5 \mathrm{mg} \mathrm{L}^{-1}$. This is in the same range as laccase yields in yeast hosts, such as Pleurotus ostreatus laccases in Kluyveromyces lactis with around $2 \mathrm{mg} \mathrm{L}^{-1}$ or Ganoderma lucidum laccase in Pichia pastoris with $6 \mathrm{mg} \mathrm{L}^{-1}$ (Piscitelli et al. 2005; You et al. 2014). Although yields of Lcc8 are far below recombinant laccases in filamentous ascomycetous host (see Mate and Alcalde 2015), pYMS33-12 produced sufficient amounts for characterization of Lcc8.

SDS-PAGE analysis showed two bands of $64 \mathrm{kDa}$ and $77 \mathrm{kDa}$ for Lcc8, which are larger than the theoretical molecular weight of $59.7 \mathrm{kDa}$ calculated from AAsequence. Other $C$. cinerea laccases showed a smaller molecular weight in SDS-PAGE analyses ranging from 54 to $66 \mathrm{kDa}$ for Lcc1, Lcc2 and Lcc6 (Yaver et al. 1999; Tian et al. 2014; Wang et al. 2014). The two bands in the SDS-PAGE (Fig. 2) correspond to the presence of two bands in the zymogram (Fig. 3a), both being confirmed as Lcc8 bands by LC-MS. In addition, deglycosylation experiment of purified Lcc8 with PNGase F did not result in a single band. Thus, the hypothesis of a glycosylation impact on the molecular weight difference as shown by several previous works on recombinant laccases (Otterbein et al. 2000; Sigoillot et al. 2004; Madzak et al. 2005) can be discarded. Also a missing cleavage of the Lcc1 signal peptide, which has a calculated molecular weight of less than $3 \mathrm{kDa}$, could not led to a molecular weight difference of $13 \mathrm{kD}$. Intron retention during splicing would also result in a larger molecule. However, in the $l c c 8$ open reading frame of both sequenced $C$. cinerea genomes (AmutBmut: fgenesh1_kg.162_\#_19_\#_Locus292v1rpkm600.11, Okayama 7: CC1G_05965T0) only one intron could be retained without facing a frame shift. This retention would lead to an Lcc8 sequence with an additional 19 amino acids accounting for around $2 \mathrm{kDa}$. Thus, the existence of two Lcc8 bands of similar intensity cannot be clarified yet.

Lcc8 showed similar characteristics to the other $C$. cinerea laccases Lcc1, Lcc2, Lcc6 and Lcc9 (Table 2); (Schneider et al. 1999; Yaver et al. 1999; Pan et al. 2014; Tian et al. 2014; Wang et al. 2014). The optimal pH of 4.0 for ABTS is similar for Lcc8 and Lcc1 (Schneider et al. 1999), while the $\mathrm{pH}$ optimum for all other analyzed $C$.

Table 2 Comparison of properties of different C. cinerea laccases

\begin{tabular}{|c|c|c|c|c|c|c|}
\hline Enzyme properties & Substrate & $\begin{array}{l}\text { Lcc1 (Schneider } \\
\text { et al. 1999) }\end{array}$ & $\begin{array}{l}\text { Lcc2 (Tian et al. } \\
\text { 2014) }\end{array}$ & $\begin{array}{l}\text { Lcc6 (Wang et al. } \\
\text { 2014) }\end{array}$ & $\begin{array}{l}\text { Lcc9 (Pan et al. } \\
\text { 2014) }\end{array}$ & Lcc8 this study \\
\hline Molecular weight [kDa] & & 66.0 & 54.0 & 57.4 & n. d. & 64 and 77 \\
\hline \multirow[t]{4}{*}{ Optimal pH } & ABTS & 4.0 & 2.6 & 3.0 & 2.5 & 4.0 \\
\hline & DMP & n. d. & n. d. & n. d. & 6.5 & 5.0 \\
\hline & guaiacol & n. d. & n. d. & n. d. & 6.5 & 4.5 \\
\hline & SGZ & 6.5 & n. d. & n. d. & 6.5 & 5.0 \\
\hline Thermal stability $\left(50^{\circ} \mathrm{C}\right)$ & & $>200 \mathrm{~min}$ & ca.50 min & $>60 \min$ & n. d. & $300 \mathrm{~min}$ \\
\hline Optimal temperature & & $60-70^{\circ} \mathrm{C}$ & $45^{\circ} \mathrm{C}$ & $40^{\circ} \mathrm{C}$ & $60^{\circ} \mathrm{C}$ & $54-63{ }^{\circ} \mathrm{C}$ \\
\hline pH stability ( $\geq 50 \%)$ & & $\begin{array}{l}7.0-10.0 \\
4{ }^{\circ} \mathrm{C}, 14 \text { days }\end{array}$ & $\begin{array}{l}2.0-11.0 \\
4^{\circ} \mathrm{C}, 24 \mathrm{~h}\end{array}$ & $\begin{array}{l}2.5-6.0 \\
4^{\circ} \mathrm{C}, 24 \mathrm{~h}\end{array}$ & $\begin{array}{l}4.5-6.5 \\
37^{\circ} \mathrm{C}, 8 \mathrm{~h}\end{array}$ & $\begin{array}{l}5.0-11.0 \\
24^{\circ} \mathrm{C}, 24 \mathrm{~h}\end{array}$ \\
\hline pl value & & 3.5 & n. d. & n. d. & n. d. & $3.3 / 3.4$ \\
\hline
\end{tabular}


cinerea laccases is lower. Lcc2 and Lcc6 show an optimal ABTS oxidation of ABTS at $\mathrm{pH} 3$ and Lcc9 at $\mathrm{pH}$ 2.5 (Table 2). For the phenolic substrates SGZ, DMP and SGZ, Lcc8 shows a lower pH optimum than Lcc1 and Lcc9 (Schneider et al. 1999; Pan et al. 2014). Generally, in comparison to all other so far characterized C. cinerea laccases, Lcc8 has a narrower optimal $\mathrm{pH}$ for the different tested substrates. The optimal range for $\mathrm{pH}$ stability for Lcc8 ( $\mathrm{pH} 5-11)$ is smaller than the range for Lcc2 $(\mathrm{pH}$ 2-11) (Tian et al. 2014), but larger than for Lcc6 (pH 3-6) (Wang et al. 2014). Nevertheless, the stability of Lcc2 was tested at $4{ }^{\circ} \mathrm{C}$, whereas Lcc 8 showed very good stability at $24{ }^{\circ} \mathrm{C}$ for $24 \mathrm{~h}$. Even after $48 \mathrm{~h}$ at $24{ }^{\circ} \mathrm{C}$, Lcc8 retained $50 \%$ of its initial activity between $\mathrm{pH}$ 6-11.

The optimal temperature for Lcc8 is comparable to those of Lcc1 and Lcc9 (Schneider et al. 1999; Pan et al. 2014) all showing highest activity against ABTS at around $60-70{ }^{\circ} \mathrm{C}$. Lcc2 was shown to have a broad temperature range with a maximum at $45{ }^{\circ} \mathrm{C}$ (Tian et al. 2014) and Lcc6 had a maximum at $40^{\circ} \mathrm{C}$ (Wang et al. 2014). Outstanding was the thermal stability of Lcc 8 at $50^{\circ} \mathrm{C}$, which was higher than for other characterized $C$. cinerea laccases (Table 2). While activity of Lcc2 (Tian et al. 2014) decreased after 60 min to less than $50 \%$, Lcc8 showed only small decrease after $60 \mathrm{~min}$ and retained $50 \%$ of its activity after $300 \mathrm{~min}$. Lcc6 (Wang et al. 2014) was only incubated for $60 \mathrm{~min}$ and, as well as Lcc8, showed only a slight reduction in laccase activity at $50{ }^{\circ} \mathrm{C}$.

Although similar to the already published $C$. cinerea laccase characteristics, Lcc8 has specific features such as a very narrow optimal $\mathrm{pH}$ range for different substrates as well as a high stability at alkaline $\mathrm{pH}$. This specificity confirm the differences between the $C$. cinerea laccases as shown previously in phylogenetic analyses (Hoegger et al. 2004, 2006; Kües and Rühl 2011). The introduced technique of $\mathrm{N}$-terminal signal peptide substitution in $C$. cinerea can help to produce other laccases not secreted by wildtype $C$. cinerea strains or even by other fungi of the phylum Basidiomycota.

\section{Additional file}

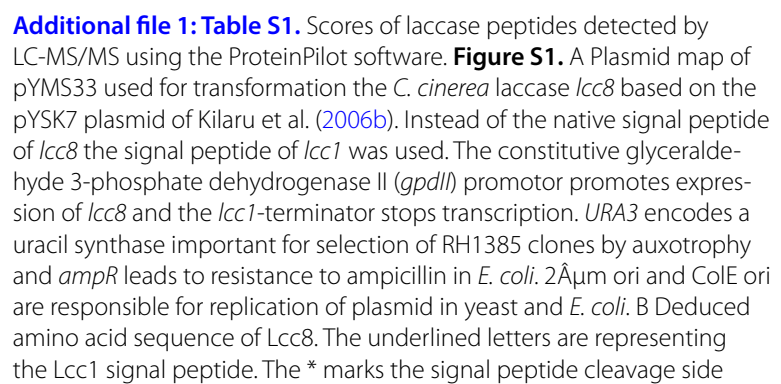

predicted by SignalP 4.1 followed by twelve additional amino acids of the Lcc1 sequence as a linker. The histidine and cysteine highlighted in red boxes are involved in copper binding according to Kilaru et al. (2006a). Putative N-glycosylation sites are highlighted in green boxes. Figure S2. Alignment of C. cinerea deduced amino acid sequences of long Lcc8 (Cci_ longLcc8, Accession number: A8N417), Lcc8 (Cci_Lcc8, Accession number: BK004118) and Lcc8 with the Lcc1 signal peptide (Cci_Lcc1SP_Lcc8).

\section{Abbreviations}

ABTS: 2,2'-azino-bis(3-ethylbenzothiazoline-6-sulfonic acid) diammonium salt; AEX: anion exchange chromatography; DHPPA: 3,4-dihydroxyhydrocinnamic acid; HIC: hydrophobic interaction chromatography; IEF: isoelectric focusing; MBTH: 3-methyl-2-benzothiazolinone-hydrazone hydrochloride; LC-MS: liquid chromatography-ESI coupled to mass spectrometer.

\section{Authors' contributions}

MS and MR conceived the study. MS and LG performed the experiments with the help of MR. AM performed the protein identification. MS, MR and AM wrote the manuscript. All authors read and approved the final manuscript.

\section{Author details}

${ }^{1}$ Institute of Food Chemistry and Food Biotechnology, Justus Liebig University Giessen, Heinrich-Buff-Ring 17, 35392 Giessen, Germany. ${ }^{2}$ Molecular Wood Biotechnology and Technical Mycology, Büsgen-Institute, University of Goettingen, Büsgenweg 2, 37077 Goettingen, Germany.

\section{Acknowledgements}

We thank Ursula Kües and Sreedhar Kilaru for providing the expression plasmid pYSK7 and the marker plasmid pCc1001.

\section{Competing interests}

The authors declare that they have no competing interests.

\section{Availability of data and materials}

The dataset supporting the conclusions of this article are included within the article and as additional file.

\section{Consent for publication}

Not applicable.

\section{Ethics approval and consent to participate}

Not applicable.

\section{Funding}

We thank the German Science Foundation (DFG) and Ministry of Science and Culture of Lower Saxony (MWK Hannover) for founding of nanoLC and High Resolution Mass Spectrometer (Eksigent 425 and TripleTOF 5600+, Sciex, Framingham MA, USA) grant INST 186/1085-1 FUGG (to U. Kües). Part of this work was supported by the ERA Net Euro TransBio commission of the Federal Ministry of Education and Research (Grant 031A506B). The authors are thankful for this support.

\section{Publisher's Note}

Springer Nature remains neutral with regard to jurisdictional claims in published maps and institutional affiliations.

Received: 28 January 2019 Accepted: 5 March 2019

Published online: 15 March 2019

\section{References}

Alves AMCR, Record E, Lomascolo A, Scholtmeijer K, Asther M, Wessels JGH, Wosten HAB (2004) Highly efficient production of laccase by the basidiomycete Pycnoporus cinnabarinus. Appl Environ Microbiol 70:6379-6384 Baldrian P (2006) Fungal laccases_occurrence and properties. FEMS Microbiol $\operatorname{Rev} 30: 215-242$ 
Blum H, Beier H, Gross HJ (1987) Improved silver staining of plant-proteins, RNA and DNA in polyacrylamide gels. Electrophoresis 8:93-99

Bollag JM, Leonowicz A (1984) Comparative studies of extracellular fungal laccases. Appl Environ Microbiol 48:849-854

Claus H (2004) Laccases: structure, reactions, distribution. Micron 35:93-96

de Souza CGM, Tychanowicz GK, de Souza DF, Peralta RM (2004) Production of laccase isoforms by Pleurotus pulmonarius in response to presence of phenolic and aromatic compounds. J Basic Microbiol 44:129-136

Dörnte B, Kües U (2012) Reliability in transformation of the basidiomycete Coprinopsis cinerea. Curr Trends Biotechnol Pharm 6:340-355

Dörnte B, Kües U (2013) Fast Microwave-based DNA extraction from vegetative mycelium and fruiting body tissues of Agaricomycetes for PCR amplification. Curr Trends Biotechnol Pharm 7:825-836

Dörnte B, Kües U (2016) Paradoxical performance of tryptophan synthase gene $\operatorname{trp}^{1+}$ in transformations of the basidiomycete Coprinopsis cinerea. Appl Microbiol Biotechnol 100:8789-8807

Dyballa N, Metzger S (2009) Fast and sensitive colloidal Coomassie G-250 staining for proteins in polyacrylamide gels. Jove J Vis Exp 30:1431

Eggert C, Temp U, Eriksson KEL (1996) The ligninolytic system of the white rot fungus Pycnoporus cinnabarinus: purification and characterization of the laccase. Appl Environ Microb 62:1151-1158

Galperin I, Javeed A, Luig H, Lochnit G, Rühl M (2016) An aryl-alcohol oxidase of Pleurotus sapidus: heterologous expression, characterization, and application in a 2-enzyme system. Appl Microbiol Biotechnol 100:8021-8030

Giardina P, Faraco V, Pezzella C, Piscitelli A, Vanhulle S, Sannia G (2010) Laccases: a never-ending story. Cell Mol Life Sci 67:369-385

Gietz RD, Schiestl RH (2007) High-efficiency yeast transformation using the LiAc/SS carrier DNA/PEG method. Nat Protoc 2:31-34

Gundry RL, White MY, Murray Cl, Kane LA, Fu Q, Stanley BA, van Eyk JE (2009) Preparation of proteins and peptides for mass spectrometry analysis in a bottom-up proteomics workflow. Curr Protoc Mol Biol 88:10.25.1-10.25.23

Hoegger PJ, Navarro-González M, Kilaru S, Hoffmann M, Westbrook ED, Kües U (2004) The laccase gene family in Coprinopsis cinerea (Coprinus cinereus). Curr Genet 45:9-18

Hoegger PJ, Kilaru S, James T, Thacker J, Kües U (2006) Phylogenetic comparison and classification of laccase and related multicopper oxidase protein sequences. FEBS J 273:2308-2326

Hong F, Meinander NQ, Jonsson LJ (2002) Fermentation strategies for improved heterologous expression of laccase in Pichia pastoris. Biotechnol Bioeng 79:438-449

Hong YZ, Zhou HM, Tu XM, Li JF, Xiao YZ (2007) Cloning of a laccase gene from a novel basidiomycete Trametes sp 420 and its heterologous expression in Pichia pastoris. Curr Microbiol 54:260-265

Hu J, Zhang Y, Xu Y, Sun Q, Liu J, Fang W, Xiao Y, Kües U, Fang Z (2018) Gongronella sp. w5 elevates Coprinopsis cinerea laccase production by carbon source syntrophism and secondary metabolite induction. Appl Microbiol Biotechnol. https://doi.org/10.1007/s00253-018-9469-4

Johannes C, Majcherczyk A (2000) Laccase activity tests and laccase inhibitors. J Biotechnol 78:193-199

Kiiskinen LL, Kruus K, Bailey M, Ylosmaki E, Siika-aho M, Saloheimo M (2004) Expression of Melanocarpus albomyces laccase in Trichoderma reesei and characterization of the purified enzyme. Microbiol 150:3065-3074

Kilaru S, Hoegger PJ, Kües U (2006a) The laccase multi-gene family in Coprinopsis cinerea has seventeen different members that divide into two distinct subfamilies. Curr Genet 50:45-60

Kilaru S, Hoegger PJ, Majcherczyk A, Burns C, Shishido K, Bailey A, Foster GD, Kües U (2006b) Expression of laccase gene Icc1 in Coprinopsis cinerea under control of various basidiomycetous promoters. Appl Microbiol Biotechnol 71:200-210

Kües U, Rühl M (2011) Multiple multi-copper oxidase gene families in basidiomycetes - what for? Curr Genomics 12:72-94

Laemmli UK (1970) Cleavage of structural proteins during the assembly of the head of bacteriophage T4. Nature 227:680-685

Larrondo LF, Avila M, Salas L, Cullen D, Vicuna R (2003) Heterologous expression of laccase CDNA from Ceriporiopsis subvermispora yields copper-activated apoprotein and complex isoform patterns. Microbiol 149:1177-1182
Leonowicz A, Cho NS, Luterek J, Wilkolazka A, Wojtas-Wasilewska M, Matuszewska A, Hofrichter M, Wesenberg D, Rogalski J (2001) Fungal laccase: properties and activity on lignin. J Basic Microbiol 41:185-227

Liu D, Coloe S, Baird R, Pedersen J (2000) Rapid Mini-Preparation of Fungal DNA for PCR. J Clin Microbiol 38:471

Madzak C, Otterbein L, Chamkha M, Moukha S, Asther M, Gaillardin C, Beckerich JM (2005) Heterologous production of a laccase from the basidiomycete Pycnoporus cinnabarinus in the dimorphic yeast Yarrowia lipolytica. FEMS Yeast Res 5:635-646

Mate DM, Alcalde M (2015) Laccase engineering: from rational design to directed evolution. Biotechnol Advanc 33:25-40

Matsumura E, Yamamoto E, Numata A, Kawano T, Shin T, Murao S (1986) Structures of the laccase-catalyzed oxidation products of hydroxy benzoic acids in the presence of ABTS (2,2'-azino-di-(3-ethylbenzothiazoline6-sulfonic acid)). Agr Biol Chem Tokyo 50:1355-1357

Messerschmidt A (ed) (1997) Multi-copper oxidases. World Scientific, Singapore

Mösch HU, Graf R, Schmidheini T, Braus G (1990) Three GCN4 responsive elements act synergistically as upstream and as TATA-like elements in the yeast TRP4 promoter. EMBO J 9:2951-2957

Otterbein L, Record E, Longhi S, Asther M, Moukha S (2000) Molecular cloning of the cDNA encoding laccase from Pycnoporus cinnabarinus 1-937 and expression in Pichia pastoris. Eur J Biochem 267:1619-1625

Pan K, Zhao N, Yin Q, Zhang T, Xu X, Fang W, Hong Y, Fang Z, Xiao Y (2014) Induction of a laccase Lcc9 from Coprinopsis cinerea by fungal coculture and its application on indigo dye decolorization. Bioresource Technol 162:45-52

Petersen TN, Brunak S, von Heijne G, Nielsen H (2011) SignalP 4.0: discriminating signal peptides from transmembrane regions. Nat Meth 8:785-786

Piscitelli A, Giardina P, Mazzoni C, Sannia G (2005) Recombinant expression of Pleurotus ostreatus laccases in Kluyveromyces lactis and Saccharomyces cerevisiae. Appl Microbiol Biotechnol 69:428-439

Rappsilber J, Mann M, Ishihama Y (2007) Protocol for micro-purification, enrichment, pre-fractionation and storage of peptides for proteomics using StageTips. Nat Protoc 2:1896-1906

Rühl M, Majcherczyk A, Kües U (2013) Lcc1 and Lcc5 are the main laccases secreted in liquid cultures of Coprinopsis cinerea strains. Anton Leeuw 103:1029-1039

Rühl M, Lange K, Kües U (2018) Laccase production and pellet morphology of Coprinopsis cinerea. Appl Microbiol Biotechnol 102:7849-7863

Schneider P, Caspersen MB, Mondorf K, Halkier T, Skov LK, Østergaard PR, Brown KM, Brown SH, Xu F (1999) Characterization of Coprinus cinereus laccase. Enzyme Microb Tech 25:502-508

Sigoillot C, Record E, Belle V, Robert JL, Levasseur A, Punt PJ, van den Hondel CAMJJ, Fournel A, Sigoillot JC, Asther M (2004) Natural and recombinant fungal laccases for paper pulp bleaching. Appl Microbiol Biotechnol 64:346-352

Slomczynski D, Nakas JP, Tanenbaum SW (1995) Production and characterization of laccase from Botrytis cinerea 61-34. Appl Environ Microb 61:907-912

Tian YS, Xu H, Peng RH, Yao QH, Wang RT (2014) Heterologous expression and characterization of laccase 2 from Coprinopsis cinerea capable of decolourizing different recalcitrant dyes. Biotechnol Biotec Eq 28:248-258

Wang B, Wang L, Lin Y, Han Q, Han J, Gao J, Tian Y, Zhao W, Peng R, Yao Q (2014) Purification and characterization of laccase from Coprinopsis cinerea in Pichia pastoris. World J Microb Biot 30:1199-1206

Wariishi H, Valli K, Gold MH (1992) Manganese(II) oxidation by manganese peroxidase from the basidiomycete Phanerochaete chrysosporium - kinetic mechanism and role of chelators. J Biol Chem 267:23688-23695

Yaver DS, Overjero MdC, Xu F, Nelson BA, Brown KM, Halkier T, Bernauer S, Brown SH, Kaupinnen S (1999) Molecular characterization of laccase genes from the basidiomycete Coprinus cinereus and heterologous expression of the laccase Lcc1. Appl Environ Microbiol 65:4943-4948

You L-F, Liu Z-M, Lin J-F, Guo L-Q, Huang X-L, Yang H-X (2014) Molecular cloning of a laccase gene from Ganoderma lucidum and heterologous expression in Pichia pastoris. J Basic Microbiol 54:134-141 